\title{
A controlled clinical study of a two-trocar mini-laparoscopic technique versus the standard laparoscopic technique in treatment of adult renal cysts
}

\author{
Xu-Hui Zhu ${ }^{1,2}$, Xin Zhang ${ }^{1,2}$, Xiu-Wu Han ${ }^{1,2}$, Peng Zhang ${ }^{1,2}$, Si-Yuan Wang ${ }^{1,2}$, Yan-Sheng Li ${ }^{1,2}$, Gao Li ${ }^{1,2}$, \\ Yuan-Hao Chen ${ }^{1,2}$ \\ ${ }^{1}$ Institute of Urology, Capital Medical University, Beijing, China \\ 2Department of Urology, Beijing Chao-yang Hospital, Capital Medical University, Beijing, China
}

Videosurgery Miniinv 2021; 16 (4): 728-735 DOI: https://doi.org/10.5114/wiitm.2021.104173

\begin{abstract}
Introduction: Laparoscopic renal cyst decortication is currently the best choice for the treatment of simple renal cysts and is widely used in clinical practice

Aim: To investigate the safety and clinical efficacy of two-trocar mini-laparoscopic decortication of adult renal cysts. Material and methods: A total of 90 patients were enrolled in the study and randomly divided into two groups: a two-trocar mini-laparoscopic treatment group (M group) and a three-trocar standard laparoscopic treatment group (S group), with 45 patients in each group.

Results: The average length of hospital stay was shorter, and the demand for postoperative analgesics was less in the M group than in the S group ( $p<0.05)$. The proportion of "very satisfied" patients in the patient physical recovery satisfaction survey was significantly higher in the M group than in the S group ( $p<0.05)$. Of the 45 patients in the $M$ group, 40 successfully underwent surgery. In 3 patients, the two-trocar procedure was converted to a three-trocar procedure due to difficulty in separating perirenal adhesion for visualization. Mini-laparoscopic surgery was converted to classic laparoscopic surgery in 2 patients. In the S group, 44 patients successfully underwent the renal cyst decortication procedure. One patient underwent partial renal resection due to an intraoperative diagnosis of multilocular cystic renal cell carcinoma. Postoperative urine leakage was reported in 3 patients in the M group and two in the S group.
\end{abstract}

Conclusions: Two-trocar mini-laparoscopic treatment of renal cysts is as safe and effective as traditional laparoscopy but is associated with less cosmetic damage, leading to a better physical appearance.

Key words: renal cyst, renal cyst decortication, mini-laparoscopic surgery, two-trocar approach.

\section{Introduction}

Laparoscopic renal cyst decortication is currently the best choice for the treatment of simple renal cysts and is widely used in clinical practice [1-3]. In recent years, single-port, single-channel retroperitoneal laparoscopic surgery has been used to treat renal cysts to reduce pain and minimize concerns regarding cosmetic appearance [4-6]. However, exploring a more minimally invasive, safer, and more effective strategy to treat kidney cysts is still a pursuit for surgeons and an expectation of patients. Percutaneous intrarenal marsupialization [7] and internal drainage using a ureteroscope for treatment

\section{Address for correspondence}

Xiu-Wu Han MD, Department of Urology, Beijing Chao-yang Hospital, Capital Medical University (Western Campus), 5 Jingyuan Road, Shijingshan District, Beijing 100043, China, phone: +86 13501356960, fax: +86 13501356960, e-mail: hanxiuwu_99dr@163.com 
of parapelvic cysts [8-11] have been reported. These are useful explorations. We have used a $5 \mathrm{~mm}$ laparoscope and a $2.8-5 \mathrm{~mm}$ laparoscopic instrument (mini-laparoscopy) to treat urological diseases, such as renal cysts, varicocele, ureteropelvic junction stenosis, cryptorchidism, and polycystic kidney disease, and achieved ideal outcomes [12]. Mini-laparoscopies are most often performed for renal cyst decortications. Since March 2014, we have utilized the two-trocar $5.5 \mathrm{~mm}$ mini-laparoscopy procedure to treat adult patients with renal cysts and compared this procedure with the standard three-trocar laparoscopic surgery. The results show that two-trocar mini-laparoscopic treatment of renal cysts is as safe and effective as traditional laparoscopy but can reduce cosmetic concerns about physical appearance.

\section{Aim}

The purpose of this study is to investigate the safety and clinical efficacy of two-trocar mini-laparoscopic decortication of adult renal cysts.

\section{Material and methods}

\section{Clinical material}

A total of 90 patients with renal cysts treated between March 2014 and June 2019 were enrolled in the study. All patients were randomly divided into two groups: a two-trocar, $5.5 \mathrm{~mm}$ mini-laparoscopic treatment group ( $M$ group) and a three-trocar, $10 \mathrm{~mm}$ standard laparoscopic treatment group (S group), with 45 patients in each group. Four patients with bilateral cysts underwent staged surgery and were divided into the corresponding groups of unilateral renal cysts for statistical analysis.

The inclusion criteria were as follows: 1) All patients were diagnosed with renal cyst via urinary B-mode ultrasound, intravenous pyelogram (IVP), and renal computed tomography (CT) examination. Those with renal cystic renal cell carcinoma were excluded. 2) B-mode ultrasound and enhanced CT scanning clearly showed a cyst diameter of greater than $5 \mathrm{~cm}$ (Bosnian type I or II) or parapelvic cysts that lead to back pain or hydronephrosis. No acute infection was evident. 3) Patients without a major renal or lumbar surgery history. 4) None of the patients had serious heart, liver, lung, or brain diseases or contraindications, such as coagulation dysfunction.

\section{Surgical instruments}

The laparoscopic instruments used in group $M$ included a $5 \mathrm{~mm}$, high-definition laparoscope (Olympus), $5.5 \mathrm{~mm}$ and $5.5 \mathrm{~mm}$ trocars, $2.8 \mathrm{~mm}$ separating pliers, a needle holder, an electrical hook, scissors, and a suction irrigation device.

The laparoscopic instruments used in group S included a $10 \mathrm{~mm}$, high-definition laparoscope (Olympus), $10.5 \mathrm{~mm}$ and $5.5 \mathrm{~mm}$ trocars, $5 \mathrm{~mm}$ separating pliers, a needle holder, an electrical hook, scissors, bipolar coagulation forceps, an ultrasonic scalpel, scissors, and a suction irrigation device.

\section{Surgical procedure}

\section{Development of the retroperitoneal space}

The trocar was placed directly in the abdominal wall by puncture, and the retroperitoneal space was exposed by separation using the laparoscope under direct vision. The procedure was performed under general anesthesia. The patient was placed in the lateral recumbent position on the unaffected side with soft pillow support under the waist. A skin incision was made 1-3 cm above the crest of the ilium at the midaxillary line, reaching the subcutaneous fascia. The trocar was placed perpendicular to the skin. The trocar was inserted into the retroperitoneal space and pushed forward until a loss of resistance was felt. The laparoscope was placed, and the trocar tip was adjusted to the site beneath the lumbodorsal fascia. $\mathrm{A} \mathrm{CO}_{2}$ pneumoperitoneum machine was turned on when the yellow extraperitoneal fat came into view. With the $\mathrm{CO}_{2}$ entering the retroperitoneal space, the laparoscope was swung along the lower abdominal muscle layer or lumbodorsal fascia to immediately create the retroperitoneal space. The methods for trocar placement and creation of the retroperitoneal space were the same in both groups. The difference was the length of the incision and the diameter of the trocars and the laparoscope, which were $5 \mathrm{~mm}, 5.5 \mathrm{~mm}$, and $5 \mathrm{~mm}$ in diameter, respectively, in group $M$, and $10 \mathrm{~mm}, 10.5 \mathrm{~mm}$, and $10 \mathrm{~mm}$, respectively, in group $\mathrm{S}$.

\section{Trocar placement}

Under the guidance of the laparoscope, two $5.5 \mathrm{~mm}$ trocars were placed approximately $2-4 \mathrm{~cm}$ below the costal margin at the posterior and anterior axillary line in group $\mathrm{S}$, while only a $5.5 \mathrm{~mm}$ trocar 


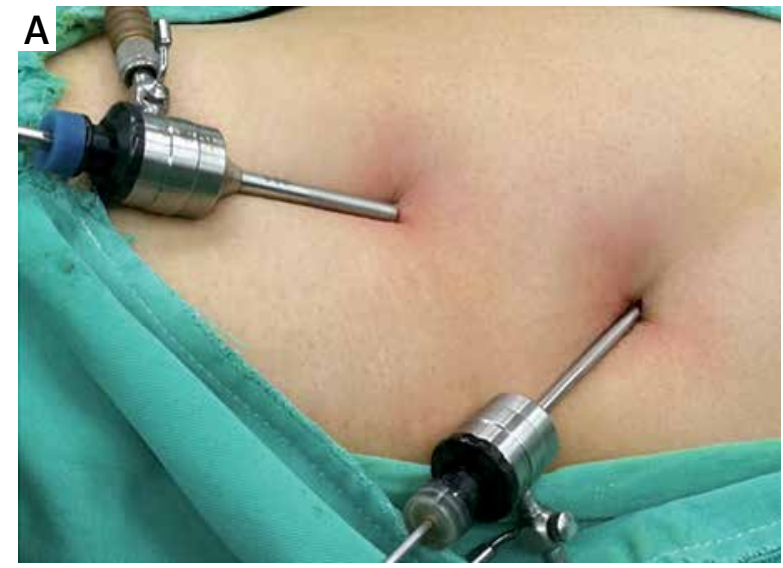

Photo 1. Trocar placement in the two-trocar approach ( $\mathrm{M}$ group, $\mathbf{A}$ ) and suspension traction was used to remove larger cyst specimens (B)

was placed at a similar site at the posterior axillary line in group $M$ (Photo $1 \mathrm{~A}$ ).

\section{Surgical procedure}

During surgery, the perirenal fascia and adipose capsule of the kidney were incised along the surface of the psoas muscle to expose the kidney and identify the renal cyst. The cyst wall was removed $5.0 \mathrm{~mm}$ from the edge of the renal parenchyma. The cystic fluid was aspirated. The cystic wall margin was electrocauterized, and the medial cyst wall was carefully examined. If cancerous tissue was suspected, a bi-

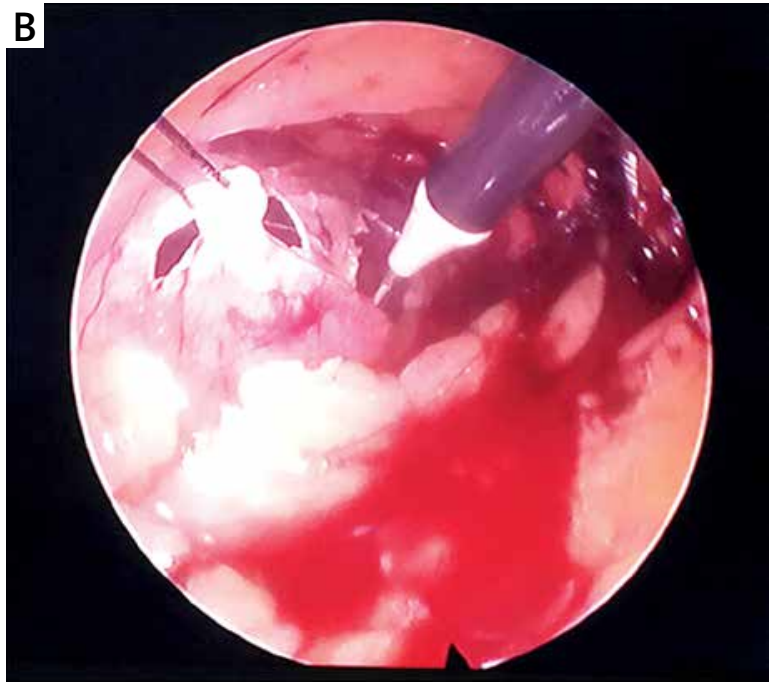

opsy was performed immediately for frozen section pathology. Small specimens were removed through the $5.5 \mathrm{~mm}$ trocar. We found that we could quickly and easily remove the larger specimens using suspension traction, i.e., a 4-0 absorbable suture was placed on the cyst wall through the trocar. The suture was retracted to maintain a certain traction tension during annular excision of the cyst wall (Photo $1 \mathrm{~B}$ ). The cyst wall was then completely removed by retraction of the suture under direct view of the scope (Photo 2). A perirenal drainage tube was placed through the incision $2-4 \mathrm{~cm}$ below the costal margin
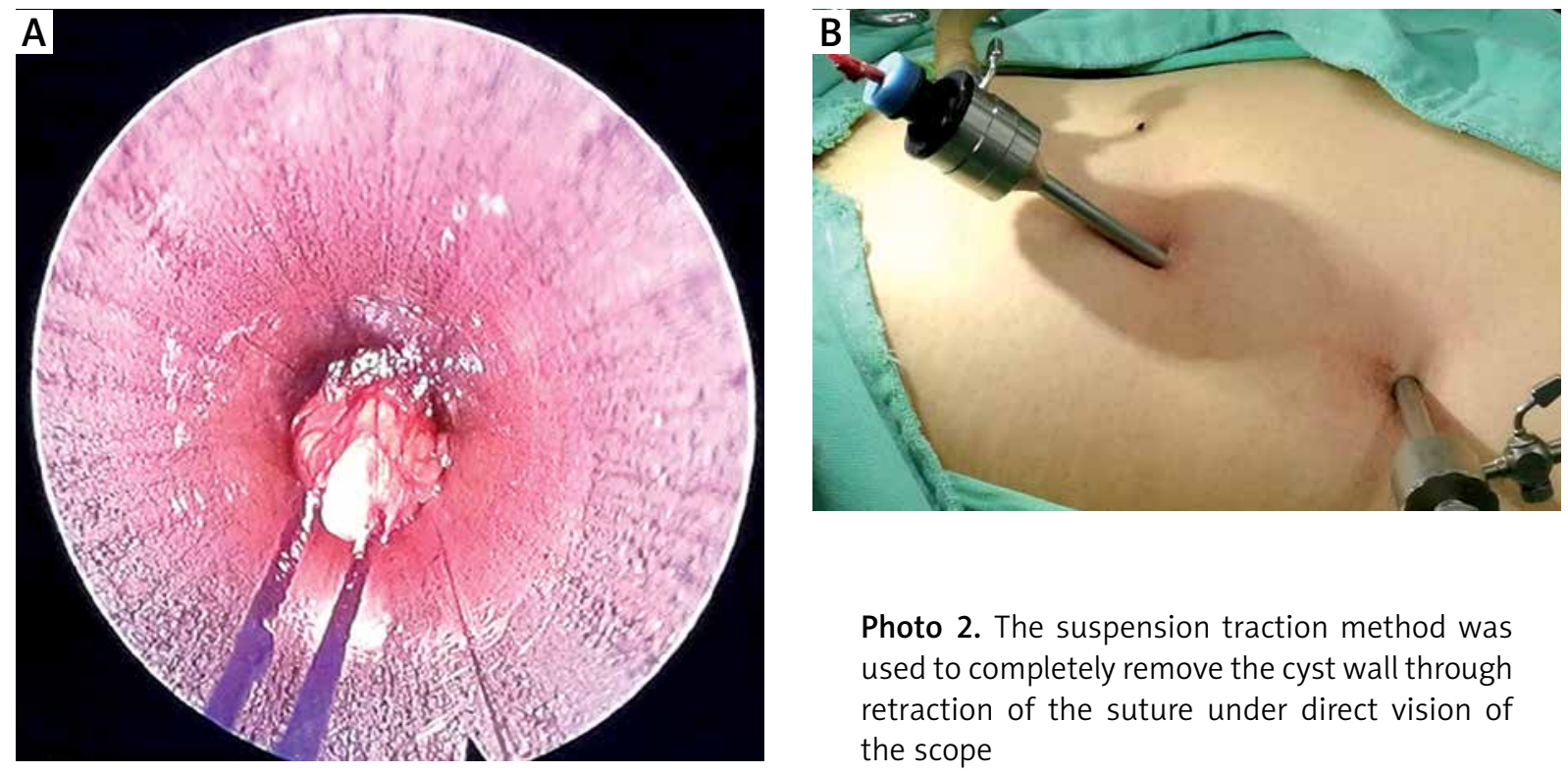

Photo 2. The suspension traction method was used to completely remove the cyst wall through retraction of the suture under direct vision of the scope 


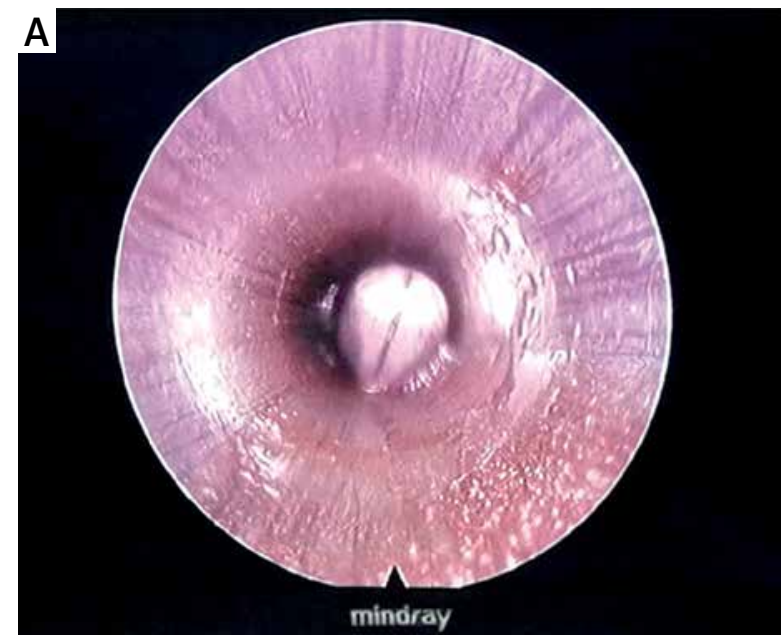

at the posterior axillary line (Photo 3). In group $M$, a needle holder or grasping forceps was used to pass the upper edge of the iliac spine via a $5.5 \mathrm{~mm}$ trocar. Under the guidance of the endoscope, it enters the trocar at the intersection with the posterior axillary line and then goes out of the body, and then introduces the drainage tube into the body from the $5.5 \mathrm{~mm}$ wound.

\section{Parameters for efficacy evaluation}

Specific parameters, namely, the operative time, intraoperative complications, rate of conversion to open surgery, estimated intraoperative blood loss, postoperative length of hospital stay, postoperative pain grading, postoperative recovery time, postoperative feeding time, time for indwelling drainage tube, incidences of urinary fistula and wound infection, and satisfaction with cosmetic outcomes, were used to evaluate the efficacy of the surgery.

If necessary, a follow-up B-ultrasound or intravenous pyelogram was performed to observe the renal cysts' improvement. Pain scores were assessed using the numeric rating scale (NRS) (0 to 10 digital pain grading). A survey that allowed four entries (very satisfied, satisfied, fair, and dissatisfied) was conducted to assess patient satisfaction with wound healing.

\section{Ethics approval and consent to participate}

The study was conducted in accordance with the Declaration of Helsinki (as revised in 2013). The study was approved by Ethics Committee of Beijing Chao-yang Hospital, Capital Medical University. All patients signed an informed consent form.

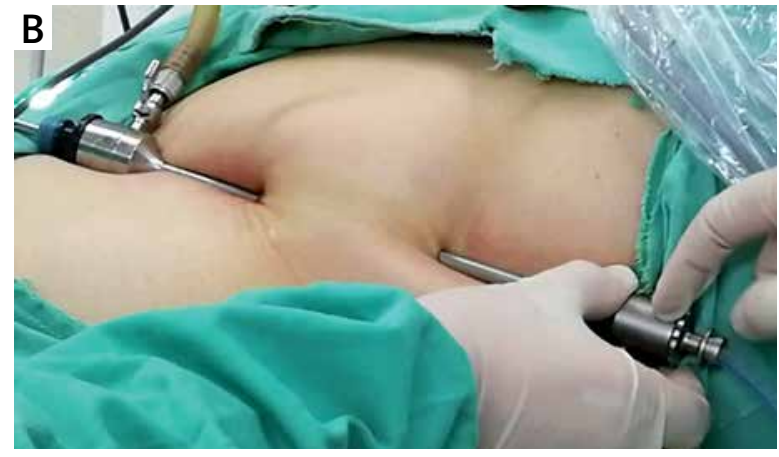

Photo 3. A perirenal drainage tube was placed through the incision 2-4 cm below the costal margin at the posterior axillary line

\section{Statistical analysis}

SPSS 17.0 software was used for data analysis. Qualitative data were compared between the two groups using the $\chi^{2}$ test. Differences in quantitative data between the two groups were compared using the Mann-Whitney rank-sum test. $P<0.05$ was considered statistically significant.

\section{Results}

There were no differences in patient gender, age, body mass index (BMI), affected kidney, clinical symptoms or size, number, and cyst location between the two groups ( $p>0.05$, Table I). Among the 45 patients in group $M, 40$ successfully underwent surgery. In 3 patients, the two-trocar procedure was converted to a three-trocar procedure (using an ultrasonic scalpel) due to difficulty in separating perirenal adhesions for visualization. In 2 patients, mini-laparoscopic surgery was converted to classic laparoscopic surgery in 1 patient with soap-like changes in perirenal fat (very hard to separate). In another patient with a hemorrhage of the lumbar vein, the two-trocar mini-laparoscopy was immediately converted to traditional laparoscopy. An ultrasonic scalpel and bipolar coagulation forceps were used for homeostasis, and the renal cyst decortication was then complete. Among the 45 patients in group S, 44 successfully underwent surgery. Suspected tumor lesions in a patient during surgery were confirmed by intraoperative frozen section pathology as multiple cystic renal cell carcinoma. Laparoscopic partial nephrectomy was then performed. Postoperative follow-up was 
Table I. Clinical data of patients in the two groups

\begin{tabular}{|c|c|c|c|}
\hline Items & M & $S$ & $P$-value \\
\hline Number of patients & 45 & 45 & \\
\hline $\operatorname{Sex}(M / F)$ & 28/17 & $22 / 23$ & \\
\hline Age [years] & $\begin{array}{c}47.5 \\
(35-74)\end{array}$ & $\begin{array}{c}49.15 \\
(34-77)\end{array}$ & 0.138 \\
\hline $\mathrm{BMI}\left[\mathrm{kg} / \mathrm{m}^{2}\right]$ & $\begin{array}{c}19.5 \\
(15.0-24.5)\end{array}$ & $\begin{array}{c}19.0 \\
(15.5-21.5)\end{array}$ & 0.825 \\
\hline Left/right $(n)$ & $20 / 25$ & $24 / 21$ & 0.951 \\
\hline Size of renal cyst [mm] & $77 \pm 36$ & $80 \pm 31$ & 0.807 \\
\hline Single/multiple cyst $(n)$ & $40 / 5$ & $38 / 7$ & \\
\hline \multicolumn{4}{|l|}{ Location of renal cyst $(n)$ : } \\
\hline $\begin{array}{l}\text { Upper pole of the } \\
\text { kidney }\end{array}$ & 14 & 11 & \\
\hline $\begin{array}{l}\text { Lower pole of the } \\
\text { kidney }\end{array}$ & 12 & 13 & \\
\hline $\begin{array}{l}\text { Dorsal side of renal } \\
\text { middle pole }\end{array}$ & 11 & 11 & \\
\hline $\begin{array}{l}\text { Ventral side of renal } \\
\text { middle pole }\end{array}$ & 5 & 8 & \\
\hline Kidney peripelvic cyst & 3 & 2 & \\
\hline \multicolumn{4}{|l|}{ Clinical manifestation: } \\
\hline Back pain & 21 & 20 & \\
\hline Hematuria & 2 & 3 & \\
\hline $\begin{array}{l}\text { Related infection } \\
\text { history }\end{array}$ & 3 & 2 & \\
\hline Asymptomatic & 19 & 20 & \\
\hline
\end{tabular}

$B M I$ - body mass index.

performed for 13 months. B-mode ultrasound and CT examination showed no signs of cyst or tumor recurrence.

Three patients in group $M$ and two in group $S$ reported persistent urine leakage. This subsided 412 days after placement of an indwelling double-J tube. Postoperative B-mode ultrasound and CT were performed and showed no sign of the cyst. Peritoneal effusion occurred in 3 patients in each group. The postoperative pathological examination showed simple renal cyst changes in all patients, except for 1 patient in group $\mathrm{S}$. There were no significant differences in the operative time, intraoperative blood loss, postoperative complications, or surgical success rate between the two groups $(p>0.05)$. The average length of hospital stay was shorter, and the demand for postoperative analgesics was less in group $M$ than in group $S(p<0.05)$.
Table II. Perioperative and postoperative clinical data of patients in the two groups

\begin{tabular}{|c|c|c|c|}
\hline Items & M & $S$ & $P$-value \\
\hline Number of patients & 45 & 45 & \\
\hline $\begin{array}{l}\text { Trauma caused by instru- } \\
\text { ments }[\mathrm{cm}]\end{array}$ & 11.5 & 20.5 & \\
\hline Operative time $[\mathrm{min}]^{*}$ & $42 \pm 15$ & $40 \pm 12$ & 0.435 \\
\hline $\begin{array}{l}\text { Intraoperative blood loss* } \\
{[\mathrm{ml}]}\end{array}$ & $25 \pm 10$ & $20 \pm 10$ & 0.859 \\
\hline $\begin{array}{l}\text { Conversion to three-trocar } \\
\text { surgery }\end{array}$ & 3 & 0 & \\
\hline $\begin{array}{l}\text { Conversion to traditional } \\
\text { laparoscopy }\end{array}$ & 2 & 11 & \\
\hline Surgery success rate (\%) & 100 & 100 & \\
\hline $\begin{array}{l}\text { Extra analgesic after } \\
\text { surgery }(n)\end{array}$ & 1 & 6 & $0.044^{\#}$ \\
\hline $\begin{array}{l}\text { Time for indwelling drain- } \\
\text { age tube, median, [days] }\end{array}$ & $3.0(2-6)$ & $4.5(2-6)$ & 0.437 \\
\hline $\begin{array}{l}\text { Time to feeding, median } \\
\text { [days] }\end{array}$ & $1.2(1-2)$ & $1.8(1-3)$ & \\
\hline $\begin{array}{l}\text { Mean NRS on first postop- } \\
\text { erative day }\end{array}$ & $2.0(1-4)$ & $5.8(3-7)$ & $0.048^{\#}$ \\
\hline NRS on discharge & $1(0-3)$ & $2(0-6)$ & 0.238 \\
\hline $\begin{array}{l}\text { Length of hospital stay, } \\
\text { median, [days] }\end{array}$ & $3(2-7)$ & $6(4-10)$ & $0.039 \#$ \\
\hline \multicolumn{4}{|l|}{ Complications: } \\
\hline Fever & 3 & 5 & \\
\hline Urine leak & 3 & 2 & \\
\hline Hematuria & 1 & 1 & \\
\hline Wound infection & 1 & 2 & \\
\hline Ureteral stenosis & 0 & 0 & \\
\hline Perirenal effusion & 3 & 3 & \\
\hline Malignant after operation & 0 & 1 & \\
\hline $\begin{array}{l}\text { Very satisfied with wound } \\
\text { recovery (\%) }\end{array}$ & 100 & 60 & $0.042^{\#}$ \\
\hline Surgery cure rate (\%) & 100 & 100 & \\
\hline
\end{tabular}

NRS - 0 to 10 numerical pain rating scale, BMI - body mass index. *In group $S$, patients with partial nephrectomy were not included in the statistical analysis. ${ }^{\sharp} P<0.05$.

The mean NRS on the first postoperative day was less in group $M$ than in group $S(p<0.05)$. The follow-up period ranged from 6 to 36 months. There was no significant difference in the surgical cure rate $(p>0.05)$. The number of patients who were "very satisfied" according to the physical recovery satisfaction survey was significantly higher in group $M$ than in group $S(p<0.05)$ (Table II). 


\section{Discussion}

Simple renal cysts have a higher incidence and are generally considered a benign congenital disease. However, larger cysts can compress and change the kidney's shape and function and compress surrounding tissues, leading to infection, effusion, and obstruction. This condition requires treatment. Open surgery for renal cyst treatment is now rarely used. Interventions via percutaneous puncture aspiration and sclerotherapy are minimally invasive and easily accepted by patients. However, the recurrence rate is high. Thus, they are not effective methods $[13,14]$ and may increase difficulties during any future surgical treatment. Shao et al. reported percutaneous intrarenal marsupialization for treatment of pararenal cysts [7]. They punctured the renal cyst using a $20.8 \mathrm{~F}$ percutaneous nephroscope under B-mode ultrasound guidance and made a $1.5-4 \mathrm{~cm}$ incision in the renal collecting duct system using a $2 \mu \mathrm{m}$ laser scalpel to drain the cyst. During 3-36 months of follow-up, the cyst subsided in 18 of the 31 patients, and the cyst size decreased in the remaining 13 patients. Flexible ureteroscopic management of symptomatic renal cysts has shown good clinical outcomes [8-11]. Yu reported a cure rate of $74.3 \%$ using ureteroscopy and laser incision drainage for treatment of parapelvic cysts (26/35) [9]. Percutaneous nephroscopy and ureteroscopic incisions can only be applied for parapelvic cysts close to the collection system and cannot be applied for the more common renal parenchymal cysts.

Foreign researcher Gaur and domestic researcher Yang reported using a $5.0 \mathrm{~mm}$ mini-laparoscopic approach for renal cyst treatment $[15,16]$. In the mini-laparoscope used in this study, the resolution and contrast of the $5 \mathrm{~mm}$ viewing scope were similar to those of a $10 \mathrm{~mm}$ conventional laparoscope, but the diameter of the former was smaller. Delicacy during the operation is required to avoid damage. Mini-laparoscopic surgery is similar to traditional laparoscopy, but the wound length is reduced by more than half. Single-port laparoscopy requires a crossing operation of curved instruments. Instrument conflict is common because two instruments are operating in the same channel, which is quite different from traditional laparoscopy. Although only one incision is required in single-port laparoscopy, the incision's length is typically greater than 25$30 \mathrm{~mm}$ [4-6]. Compared with single-port laparosco- py, the length of each incision for trocar placement in mini-laparoscopy is $5.5 \mathrm{~mm}$, with a total incision length of only $11 \mathrm{~mm}$.

The keys to creating a retroperitoneal space using the mini-laparoscopic technique are as follows: 1) the trocar is placed perpendicularly through a minimal incision; 2) the trocar is placed into a site under the abdominal wall, and the retroperitoneal space is then directly created by swinging the scope body; 3) large cyst wall specimens are removed by suspension traction. The largest skin incision required for completion of the procedure is only $5.5 \mathrm{~mm}$ in diameter, thus achieving minimal abdominal wall trauma. The placement of the laparoscopic trocar is modified from a traditional triangular relationship (three-trocar method) to a point-to-point linear relationship (two-trocar method). The two-trocar method can be used to replace the suction or separating forceps by means of a swing separation of the laparoscopic body itself to dissect perirenal fat or renal cysts, thereby skipping the creation of an operating channel and further reducing damage to the patient. Furthermore, one surgeon, rather than two, can complete the surgery. The advantage of the two-trocar method is that the skin incisions are small and concealed. The trauma of the operation to the patient is reduced compared with conventional laparoscopic surgery. The postoperative scar is small and nearly invisible or disappears, and the cosmetic benefit is obvious (Photo 4). Thus, the average length of hospital stay was shorter, the demand for postoperative analgesics was less, and the mean NRS on the first postoperative day was less in group $M$ than in group $S(p<0.05)$. The number of patients "very satisfied," according to the physical recovery satisfaction survey, was significantly higher in group $M$ than in group $S(p<0.05)$.

However, this increases the difficulty of the operation. The surgeon needs intensive training to overcome the habits associated with the original operation and adapt to the one-hand operation. In addition, with the two-hand procedure, the suture-suspension method can be used to remove the cyst completely from the sheath via traction with the suture (Photo 1). In addition, the number of operation channels is decreased by one, and thus a single-person operation becomes more difficult. Maybe it requires a longer learning curve to do it, but the learning curve is only interesting for the patient when he/she becomes free of symptoms without 

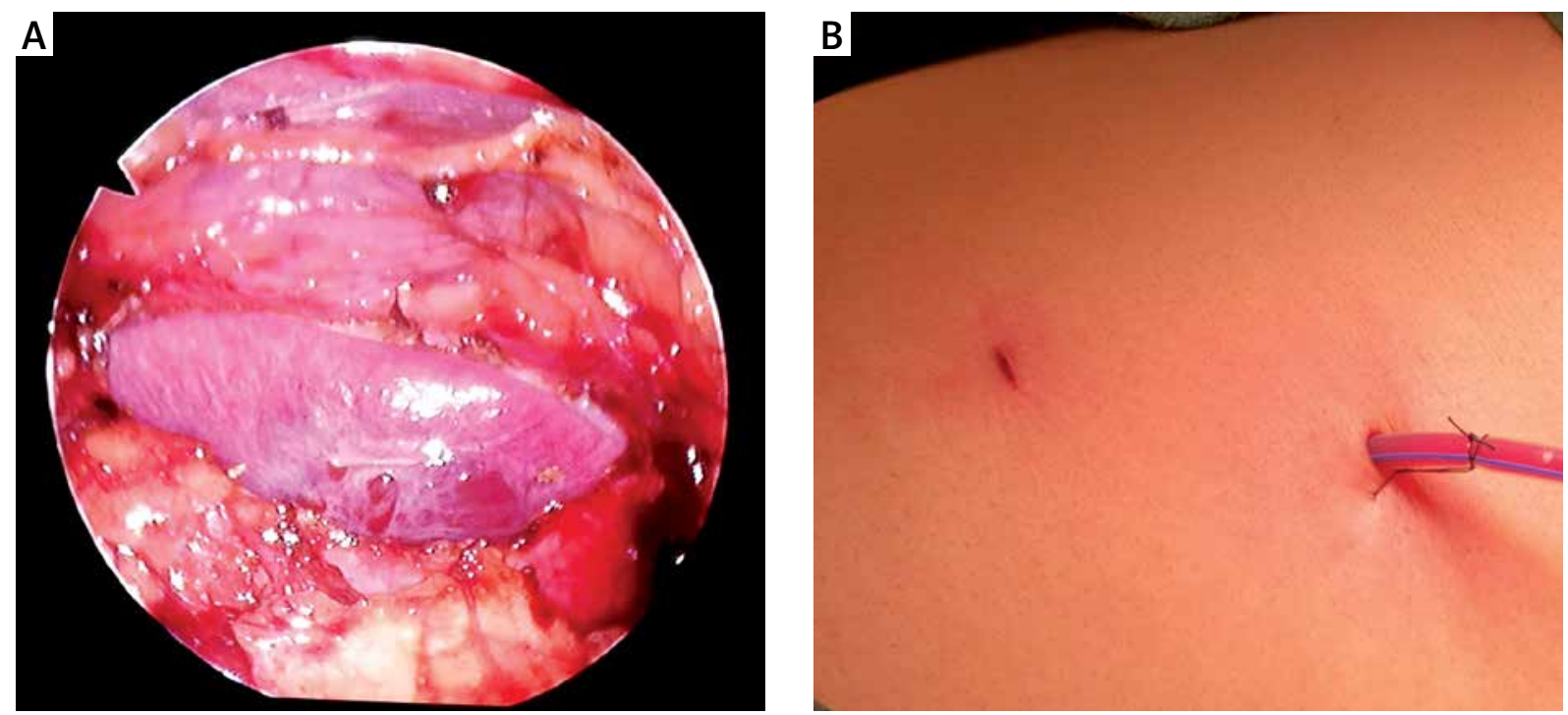

Photo 4. The residual cavity after renal cyst decortication at the end of the operation (A). The two-trocar method is associated with a small scar and reduced cosmetic concern about appearance, and only one incision was used to place the perirenal drainage tube (B)

complications. This can be achieved when the whole process proceeds correctly, which includes making the right diagnosis, defining the right indications for intervention, and choosing the best treatment method. In this way, the patient receives personalized treatment, and the learning curve related to the particular method is a part of this course. Hence, we believe that an "experience-related learning curve" is more appropriate [17, 18], so the learning curve could be shorter in experienced surgeons.

Therefore, the following aspects are important: 1) Surgical indications should be strictly assessed. Due to the absence of an ideal vascular clip applier, a relatively small grasping device, and certain difficulties in grasping and exposing tissue, each patient's condition should be carefully evaluated before surgery. For cases with complex renal cysts or malignant lesions, the two-trocar method is not applicable. The patient's safety, gains and losses, and treatment effects should always be prioritized when deciding on treatment approaches. 2) Attention should be paid to the basic training of surgeons in traditional laparoscopic surgery. The slim laparoscopic body and limited light source result in a narrow and dark view of the operative field. Flexible instrumentation and fewer operation channels require an experienced hand. Intraoperative bleeding is difficult to manage once it occurs, and immediate conversion to the three-trocar or standard laparoscopic surgery may be necessary.
This requires careful operation by surgeons experienced in laparoscopic surgery.

\section{Conclusions}

The two-trocar mini-laparoscopic decortication for the treatment of simple renal cysts is similar to traditional three-trocar laparoscopic surgery. However, it is associated with reduced trauma and a shorter learning curve and is recommended for wide clinical use.

\section{Acknowledgments}

Xu-Hui Zhu and Xin Zhang contributed equally to this study.

We would like to acknowledge the hard and dedicated work of all the staff who implemented the intervention and evaluation of components of the study.

This study was funded by the Western medicine project of "Scientific Research and Cultivation Plan of Beijing Municipal Hospitals" by Beijing Hospital Administration in 2019 (Approval Number: PX2019011). The funding body had no role in the design of the study, in collection, analysis, and interpretation of data or in writing the manuscript.

\section{Conflict of interest}

The authors declare no conflict of interest. 


\section{References}

1. Ozcan L, Polat EC, Onen E, et al. Comparison between retroperitoneal and transperitoneal approaches in the laparoscopic treatment of bosniak type i renal cysts: a retrospective study. Urol J 2015; 12: 2218-22.

2. Hinev A, Anakievski D. Laparoscopic transperitoneal renal cyst decortication. Acta Chir lugosl 2014; 61: 35-40.

3. Bas O, Nalbant I, Can Sener N, et al. Management of renal cysts. JSLS 2015; 19: e2014.00097.

4. Choi KH, Ham WS, Rha KH, et al. Laparoendoscopic single-site surgeries: a single-center experience of 171 consecutive cases. Korean J Urol 2011; 52: 31-8.

5. Mai H, Liu J, Zhao L, et al. Efficacy investigation of transpostceliac single-port 3-channel laparoscope in the treatment of complex renal cyst. Int J Clin Exp Med 2015; 8: 10031-5.

6. Yang D, Xue B, Zang Y, et al. A modified laparoendoscopic single-site renal cyst decortication: single-channel retroperitoneal laparoscopic decortication of simple renal cyst. J Laparoendosc Adv Surg Tech A 2013; 23: 506-10.

7. Shao ZQ, Guo FF, Yang WY, et al. Percutaneous intrarenal marsupialization of symptomatic peripelvic renal cysts: a single-centre experience in China. Scand J Urol 2013; 47: 118-21.

8. Li EC, Hou JQ, Yang LB, et al. Pure natural orifice translumenal endoscopic surgery management of simple renal cysts: 2 -year follow-up results. J Endourol 2011; 25: 75-80.

9. Yu W, Zhang D, He X, et al. Flexible ureteroscopic management of symptomatic renal cystic diseases. J Surg Res 2015; 196: 118-23.

10. Mao X, Xu G, Wu H, Xiao J. Ureteroscopic management of asymptomatic and symptomatic simple parapelvic renal cysts. BMC Urol 2015; 15: 48.

11. Zhao Q, Huang S, Li Q, et al. Treatment of parapelvic cyst by internal drainage technology using ureteroscope and holmium laser. West Indian Med J 2015; 64: 230-5.

12. Han XW, Shan H, Li T, et al. Comparative study between minilaparoscopic and conventional laparoscopic instruments for treatment of ureteropelvic junction obstruction. J Clin Urol 2016; 31: 45-9.

13. Cho YJ, Shin JH. Comparison of acetic acid and ethanol sclerotherapy for simple renal cysts: clinical experience with $86 \mathrm{pa}$ tients. Springerplus 2016; 5: 299.

14. Dell'Atti L. Comparison between the use of $99 \%$ ethanol and $3 \%$ polidocanol in percutaneous echoguided sclerotherapy treatment of simple renal cysts. Urol Ann 2015; 7: 310-4.

15. Gaur DD, Gopichand M, Dubey M, Jhunjhunwala V. Mini-access for retroperitoneal laparoscopy. J Laparoendosc Adv Surg Tech A 2002; 12: 313-5.

16. Yang CT, Li ZB, Du DL, et al. Comparative study of small-incision access retroperitoneoscopic technique with standard retroperitoneoscopic technique in the management of simple renal cyst. Chin J Endourol 2016; 10: 263-6.

17. Panek W, Szmer J, Kuijper CF, Chrzan R. Learning curve or experience-related outcome: what really matters in paediatric laparoscopic pyeloplasty. Videosurgery Miniinv 2020; 15: 377-81.

18. Brzoszczyk B, Milecki T, Jarzemski P, et al. Urology resident training in laparoscopic surgery - results of the first national survey in Poland. Videosurgery Miniinv 2019; 14: 433-41.

Received: 8.12.2020, accepted: 25.01.2021. 